classroom. After all, the ability to discuss contemporary affairs intelligently must be provided for all citizens, and the classroom is the only place where all may be reached.

\title{
Discussion as a Tool in Acquiring and Using Knowledge
}

\author{
JOHN KELTNER \\ University of Oklahoma \\ FRANKLYN HAIMAN \\ Northwestern University
}

$\mathrm{W}$

E HAVE learned much in recent years about the essential role of discussion in groups, institutions, or societies which aspire to democratic ideals. The values of group discussion as a method of dealing with personal and social problems of all kinds have been brought rather forcibly to the attention of those whose job it is to influence and guide human behavior. We have come to appreciate its importance as a decision-making tool in action groupsits value as a stimulator of group interest and understanding, its worth as a molder of better decisions, its effectiveness in gaining support for social policies. We have seen an ever-increasing awareness of the power of group discussion as a psychologically therapeutic device and as an instrument for the training and development of democratic leadership. Our purpose here is to explore still another of its aspects. We propose to examine discussion primarily as a tool or instrument in the acquisition and use of knowledge and information.

Many discussions, carried on in committees, boards, clubs, or other so-called action groups, are designed to evolve explicit and definite policies which are to be executed by members of the group. It is obvious that the success of such meetings depends upon specific information and knowledge of the subject being discussed. Other discussions, such as those carried on in the classroom or public forum, are not designed primarily to achieve immediate action. It is, of course, hoped that individual growth will result from such talk and that this too will eventually lead to some kind of action. Such meetings, no less than those where immediate decisions are the goal, require that information and knowledge of the subject be present if the conversation is to amount to more than a pooling of ignorance.

No effective discussion can take place without material, or without preparation, except in those therapeutic situations where the "materials" are simply the personal feelings or emotions of the members of the group. One of the 
criticisms of discussion which has held considerable popularity in the past years has been that much of our time is expended in talking about things that we know nothing about. This too of ten is the case, and it is the partial result of misunderstanding of the nature and purpose of the discussion pattern of thinking. Effective discussion requires a kind of discipline in the handling of information which is quite as rigorous as most any other form of communicative activity. Although we hope to demonstrate later in this article that the discussion method is uniquely effective in stimulating the member's research efforts, in translating words on a page into living, functional ideas, and in creating new combinations of ideas, we should like to preface these thoughts with an emphasis of that concept that, at every turn in the discussion process, information is essential.

\section{DISCUSSION PATTERNS}

To substantiate this viewpoint let us examine, for example, the discussion pattern recommended by the textbooks, based upon the John Dewey scheme of reflective thinking. By way of review, this pattern entails at least four basic steps.

1. The prime step in problem-solving is to establish a clear-cut end in view, or a basic objective toward which the discussion must reach.

2. Following the establishment of a general or basic goal, the discussion situation requires a careful analysis of the factors that are involved in the problem. This entails an understanding of the symptoms and causes of the problem and of the obstacles standing in the way of attainment of the goal.

3. Tre third phase is concerned with the examination and evaluation of possible s)lutions.

4. If and when a solution is agreed upon, it is frequently incumbent upon the discussants to proceed to a consideration of methods for putting the solution into action.

In brief, then, the basic steps through which effective discussion pass are goal-setting, analysis, solution-making, and action planning. Let us now analyze this pattern to discover at what stage or stages particular types of information may be required.

1. Before the objectives of a group can be established and discussion ensue, those members who are taking an active part must know what the purposes and possibilities of this particular discussion situation are. This is the kind of knowledge that has to do with the immediate situation. It requires that the participants and leaders know something about the people who are in this group, that they know something about the intentions of those who created the group and the responsibilities that were envisioned for it, that they know something about the nature and limitations of the subject to be discussed. Since this first stage is of tremendous importance to the effectiveness of group thinking, it is necessary that all the participants be fairly well aware of the general direction in which the group should be moving. This kind of information is an essential prerequisite to intelligent problem solving. It is a personal type of information, 
involving motives and intentions. Too of ten this aspect of the discussion and this particular kind of knowledge are over-looked.

2. At the analysis level, the greatest emphasis is on a wide and thorough understanding of factual materials, predominantly of an objective nature. Here the discussion pattern requires a careful examination of statistics, expert opinions, historical backgrounds, causative theories, and personal experiences of group members. Available information may be almost limitless. However, it is reasonable to limit consideration to those materials which are most immediately relevant to an understanding of the obstacles which stand in the way of achievement of the group's goal. When a doctor diagnoses a patient, inquiring into the symptoms and causes of the illness, his investigation is usually carried only so far as to cure the immediate ailment. Ordinarily, he does not explore the social and economic conditions that may have led to inadequate food, clothing, and shelter which may have caused weakened resistance to the disease in question.

In some group problems the depth and scope of the analysis is so complex that not one but many discussions are necessary to cover material required for an adequate understanding. All the materials, of course, can be classified into at least the two categories, evidence and reasoning, traditionally known to teachers of speech.

3. At the solution level, a somewhat different kind of information is necessary. The need is for as many ideas as can be gathered on possible ways of overcoming the obstacles and attaining the goals that have already been agreed upon. Many such ideas can be found in the writings of authorities who have given thought to the problem or other individuals or groups who have tried out various methods of dealing with similar problems. Here, too, is a need and opportunity for what might be called creative information, growing out of the interchange of ideas in the immediate group itself. The suggestions which have been brought in from outside sources and shared around the room may lead to the spontaneous development of a new possibility or of new combinations of old ones.

It is a sad fact that many discussion groups confine themselves, at this stage of the process, to a consideration of too few possibilities. Their thinking is too bound to old patterns and is not sufficiently creative. This is one phase of discussion where imaginativeness can and should be encouraged. Information needed at this stage is largely of the stimulative or speculative variety. It is not beyond reason to expect that even fiction literature might be of help at this point.

4. Action planning is largely a technical matter requiring technical knowhow. Learning groups are usually not concerned with this phase. Policy-determining groups will of ten leave this matter in the hands of experts to execute. When and if it becomes a part of the discussion, the information required usually has to do with the techniques of influencing human behavior. 
All the various types of information we have discussed can, for convenience, be placed in two broad categories. The first would include information about people who are in the group and who are concerned with what the group is doing. This information is necessary for an understanding of the functioning of the group and of its purposes. It includes such items as the vocational and special interests of the members of the group, their likes and dislikes, their values and sentiments, and their feelings toward one another.

The second category would include information about the subject being discussed by the group-facts, opinions, speculations, etc., which aid in an understanding of the problem itself. Of these two categories of information, the second has long been recognized as one of vital concern to persons about to engage in discussion or any other kind of communicative process. The first has of ten been over-looked. The second is vitally important but so is the first. Many discussions become meaningless because of a failure to understand the intents and purposes bebind the participation of the various members of the. group.

\section{UNIQUENESS OF DISCUSSION}

With this background of the relationship between the phases of discussion and the types of information required for each phase, let us now proceed to a consideration of the uniqueness of discussion as a tool for acquiring and using knowledge. As we suggested at the outset, there are at least three unique contributions that the discussion method can make to the learning process. First, it is an extremely effective motivating influence. Second, it is perhaps the only effective method for translating sheer verbal memorization into living, functional ideas which are adopted or internalized as a part of the actual behavior of the individual. Third, it is a creative force in the development of new knowledge. In the course of what follows, we hope to substantiate these claims.

Just as in preparing for any other communicative experience, would-be discussion participants should gather their materials before the meeting takes place. This may consist of reading, interviews with people involved in the problem, research projects, and observations or field trips. But unlike other communicative experiences, learning does not end when the preparatory research is done and the meeting is called to order. During the discussion, the process continues. Let us assume, for example, that in a given discussion every member of the group has carefully examined as many different sources as are available on the topic. As the discussion opens, it becomes obvious at once that, while in some cases the sources of information may be the same, there are different interpretations and understandings that come from different people reading the same information. The individual is thus enabled to re-assess his own reactions in the light of the reactions of others and, hence, come to a richer understanding of the materials to which he had exposed himself. He becomes more sensitive to 
these materials and is now able to see them from the vantage point of many angles rather than just his own. It is as though a man who was looking at the Empire State Building from the sidewalk on Fifth Avenue could suddenly be enabled, at the same time, to see it from the top of the Chrysler Building, from an airplane overhead, from the seventh floor of a building across the street, and from an office window on the sixty-first floor of the Empire State Building itself.

Another result of this process in which discussants talk over their research materials is that a more permanent, as well as a richer, understanding is attained. Knowledge that we garner from reading books and articles, or even from observing situations, is of ten of a fleeting nature, lost to us after a short period of time. When we bring it into a discussion, however, and have an opportunity to explain it to others and use it in deliberating on a problem, the information loses its isolated meaninglessness and begins to fit into a pattern. It has more reality. The individual is more likely to retain that information after such an experience than he is if the experience has not been possible.

It might also be mentioned that whenever opportunities can be provided for discussion groups that are essentially of a learning nature to engage in some kind of action as a result of their deliberations, then we can expect understanding to be still greater. When decisions and action are required, the information

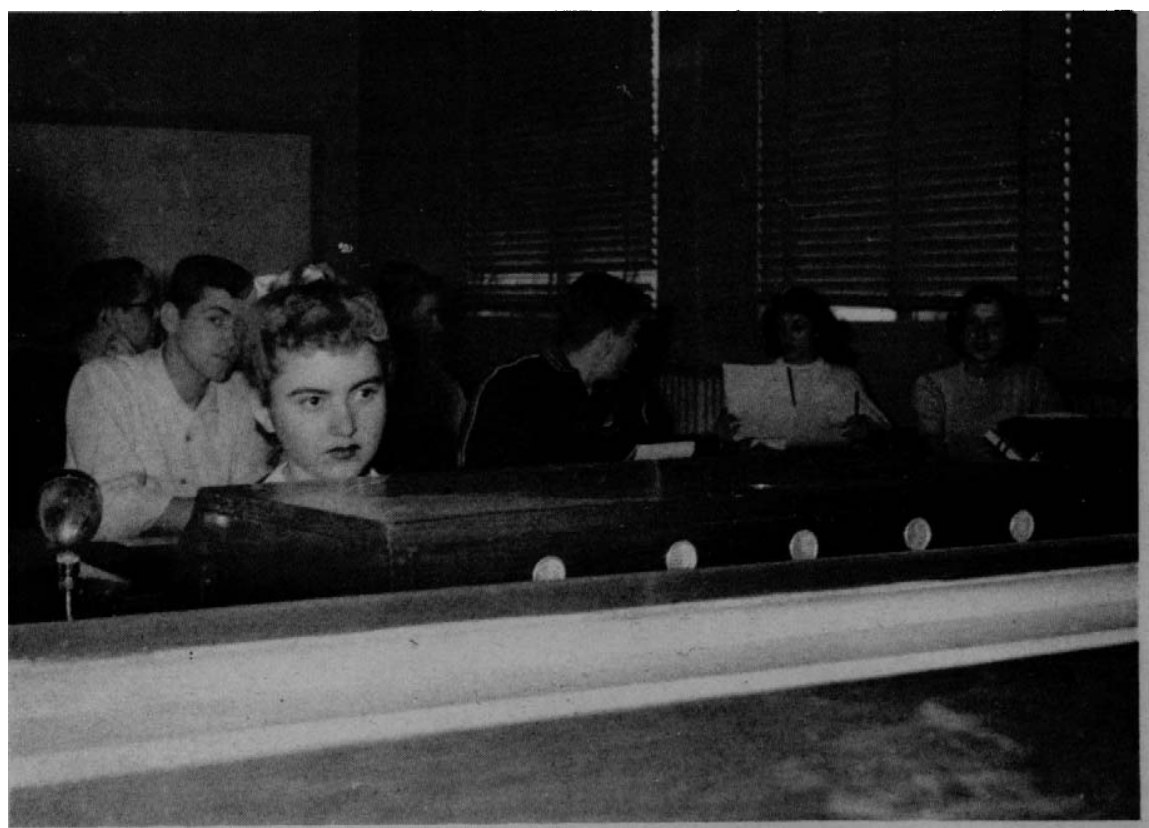

Through the control-room window, one sees a radio class using discussion as a tool in acquiring and using knowledge. 
which members of the group bring to the discussion must be even more carefully related to the total picture and, hence, take on a higher degree of meaningfulness for the person.

Discussion, properly used, requires not only information, but also information on an active level. That is to say, when a member of the group has material which he feels is worthy of sharing with other members, that material must be verbalized and presented to the group. In the process, the material becomes more a part of the person who presents it. His learning and grasp of that material increases considerably. It is just like the old speaker who always had such a big storehouse of jokes to use on various occasions. Someone asked him one day how he could remember so many jokes. His answer was quick-"When I hear a joke, I waste no time in trying to tell it to someone else. The first time I tell it to someone else, the joke is one-tenth mine. The next time I tell it to someone else, it is one-half mine, and, by the time $I$ have told it four times, that joke is all mine and nobody can take it away from me." The same is true of information developed in discussion. By the time you have discussed certain information, had it examined and looked at, even defended it or opposed it, it has become pretty much a part of you.

It is also important for us to note that (assuming that the discussion is well prepared for and properly conducted) knowledge used in the discussion process is, on the whole, knowledge which is directed at some specific aim or objective. This is a significant value in that it provides a discernible motivating factor for the acquisition and retention of information. A man who is going to need a hammer and actually uses it is more likely to know something about that hammer and how to use it than the man who only looks at the hammer and dreams about its function and use. So with information-a discussion situation provides an opportunity for individuals actually to use information in dealing with a problem.

We noted at the outset of this article that discussion is sometimes condemned because it is felt that it tends to be a pooling of ignorance. We wish to repeat as clearly as we can what we have several times implied-that no effective discussion can take place in the absence of information on the problems being discussed. Any teacher, therefore, or trainer in the field of discussion who fails to start out on the basic premise that information or knowledge of the subject is essential is in reality missing the whole point of the discussion method. The metbod alone cannot provide knowledge or information. It can provide an instrument, and a very effective one at that, for motivating the search and discovery of knowledge, for making that knowledge come alive, and for re-arranging it into meaningful creative patterns with deeper insight. Hence, good discussion is not only a tool in acquiring and using knowledge, it is also the result of knowledge properly acquired and well used. 